ACCURACY OF THE QUASISTATIC METHOD FOR

TWO-DIMENSIONAL THERMAL REACTOR TRANSIENTS WITH FEEDBACK

by

H. L. Dodds, Jr.

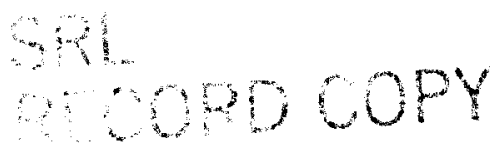

Savannah River Laboratory

E. I. du Pont de Nemours and Co.

Aiken, South Carolina 29801

Proposed for Publication as Technical Note in

Nuclear Science and Engineering

No. of text pages 17

No. of tables 4

No. of figures 5

This paper was prepared in connection with work under Contract No. AT (07-2)-1 with the U. S. Energy Research and Development Administration. By acceptance of this paper, the publisher and/or recipient acknowledges the U. S. Government's right to retain a nonexclusive, royalty-free license in and to any copyright covering this paper, along with the right to reproduce and authorize others to reproduce all or part of the copyrighted paper. 
This document was prepared in conjunction with work accomplished under Contract No. AT(07-2)-1 with the U.S. Department of Energy.

\section{DISCLAIMER}

This report was prepared as an account of work sponsored by an agency of the United States Government. Neither the United States Government nor any agency thereof, nor any of their employees, makes any warranty, express or implied, or assumes any legal liability or responsibility for the accuracy, completeness, or usefulness of any information, apparatus, product or process disclosed, or represents that its use would not infringe privately owned rights. Reference herein to any specific commercial product, process or service by trade name, trademark, manufacturer, or otherwise does not necessarily constitute or imply its endorsement, recommendation, or favoring by the United States Government or any agency

thereof. The views and opinions of authors expressed herein do not necessarily state or reflect those of the United States Government or any agency thereof.

This report has been reproduced directly from the best available copy.

Available for sale to the public, in paper, from: U.S. Department of Commerce, National Technical Information Service, 5285 Port Royal Road, Springfield, VA 22161, phone: (800)

553-6847, fax: (703) 605-6900, email: orders@ntis.fedworld.gov online ordering: http://www.ntis.gov/ordering.htm

Available electronically at http://www.doe.gov/bridge

Available for a processing fee to U.S. Department of Energy and its contractors, in paper, from: U.S. Department of Energy, Office of Scientific and Technical Information, P.O. Box 62, Oak Ridge, TN 37831-0062, phone: (865 ) 576-8401, fax: (865) 576-5728, email: reports@ adonis.osti.gov 


\title{
ACCURACY OF THE QUASISTATIC METHOD FOR \\ TWO-DIMENSIONAL THERMAL REACTOR TRANSIENTS WITH FEEDBACK
}

\author{
by \\ H. L. Dodds, Jr. \\ Savannah River Laboratory \\ E. I. du Pont de Nemours and Co. \\ Aiken, South Carolina 29801
}

\section{ABSTRACT}

The quasistatio method was compared with a direct finitedifference method of solving two-dimensional, thermal reactor transient problems with thermal-hydraulic feedback. Caloulations using both methods were performed for a cylindrical $(r-z), \mathrm{D}_{2} \mathrm{O}-$ moderated and-cooled, uranizm-fueled reactor.

This study shows that the quasistatic method is capable of producing highly accurate results, relative to the direct finitedifference method, for two-dimensional thermal reactor transients with feedback. The quasistatic method also offers the flexibility of using larger time steps between flux shape calculations without encountering numerical problems than the direct method. The quasistatic and direct method codes used in this work are comparable with respect to accuracy and computing costs except for transients with weak spatial effects. For such transients, much larger time steps can be used in the quasistatic code than in the direct method code to achieve a specified accuracy which, in turm, provides a considerable savings in computing costs. 


\section{by}

H. L. Dodds, Jr.

Savannah River Laboratory

E. I. du Pont de Nemours and Co.

Aiken, South Carolina 29801

\section{INTRODUCTION}

An important aspect in the design and safe operation of a nuclear reactor is the behavior of a reactor in a transient, or nonsteady state, condition. The models currently used to describe the neutronic and themal-hydraulic transient characteristics of a reactor consist of a rather sophisticated set of coupled partial differential equations. Conventional direct finite-difference methods are usually used to convert the differential equations to algebraic equations which are amenable for solution with the aid of a digital computer.

If the differential models involve two or three spatial dimensions (e.g., $r-z$ or $r-z-\theta$ ), the number of resulting algebraic equations can be extremely large, involving as many as a million unknowns. Such large systems of equations result in long running times and large memory requirements even on the 
present generation of computers. In short, multidimensional reactor transient calculations utilizing the direct finitedifference method of solution are quite expensive when performed on the present generation of computers.

To reduce computing costs without introducing unacceptable inaccuracies in the solution, more approximate methods of solution are being developed. One such method, developed primarily for fast reactors such as the Liquid Metal Fast Breeder Reactor is the "improved quasistatic" method.1-10 Although the accuracy of the quasistatic method is adequate for both fast reactors and thermal light-water reactors, the accuracy of the method is much better for fast reactors than for thermal 1 ight-water reactors. ${ }^{1-5}$ Previous work has also indicated that the quasistatic method could provide a significant savings in computing costs relative to the direct finite-difference method for large two- and threedimensional problems, although no definite conclusions could be drawn because most of the work involved only small one-dimensional problems. In addition, most of the previous work involving comparisons of the quasistatic method with the direct finite-difference method included only the neutronic models. The thermal-hydraulic models, commonly referred to as feedback, were not included in the calculations.

The primary objective of this work is to investigate the accuracy of the quasistatic method for solving two-dimensional, thermal (heavy-water type) reactor transient problems with feedback. A secondary objective is to investigate the computing 
efficiency of a computer code which uses the method. The basis of comparison for both accuracy and computing efficiency is a code which uses a direct finite-difference method of solution. ${ }^{11}$ Both the quasistatic code and the direct method code used in this work were developed for use primarily as research tools. ${ }^{12}$

\section{THEORETICAL MODEL}

The time-dependent, multienergy-group diffusion equations in two-dimensional $(r-z)$ geometry are used in this work to describe the neutronic behavior of a nuclear reactor. In matrix notation, these equations are

$$
\begin{aligned}
\underline{V}^{-1} \frac{\partial}{\partial t} \underline{\phi(}(\bar{r}, t) & =\left[\nabla \cdot \underline{\underline{D}}(\bar{r}, t) \nabla-\underline{A}(\bar{r}, t)+(1-\beta) \underline{x}_{p} \underline{F}^{T}(\bar{r}, t)\right] \underline{\varphi}(\bar{r}, t) \\
& +\sum_{i=1} \underline{x}_{i} \lambda_{i} C_{i}(\bar{r}, t)+\underline{S}(\bar{r}, t)
\end{aligned}
$$

and

$$
\frac{\partial}{\partial t} C_{i}(\bar{r}, t)=\beta_{i-} F^{T}(\bar{r}, t) \Phi(\bar{r}, t)-\lambda_{i} C_{i}(\bar{r}, t) \quad i=1, \cdots, M
$$

where $\bar{r}$ is the position vector, $t$ is time, and $\nabla$ is the gradient operator. $\underline{V}^{-1}$ is a $G \times G$ diagonal matrix containing the inverse velocities for $G$ energy groups. A doubly underlined quantity denotes $G \times G$ square matrix, a singly underlined quantity denotes $G \times 1$ matrix, and a scalar is denoted by a quantity with no underline. $\Phi$ is the flux vector, $\underline{D}$ is the diffusion coefficient (diagonal) matrix, and $\stackrel{A}{=}$ is the removal plus inscattering matrix. $\beta$ is the delayed neutron fraction, $\underline{x}_{p}$ is the prompt neutron fission 
spectrum, and $\mathrm{F}^{\mathrm{T}}$ denotes the transpose of the production cross section vector. $M$ denotes the number of delayed neutron precursor families, $\underline{x}_{i}$ is the delayed neutron fission spectrum, and $\lambda_{i}$ is the decay constant for precursor family $i . C_{i}$ is the precursor density for precursor family $i, \underline{S}$ is the external neutron source vector, and $\beta_{i}$ is the delayed neutron fraction for precursor family i. $\stackrel{D}{=} \stackrel{A}{=}$, and $\underline{x}_{p} \underline{F}^{T}$ are functions of the thermal-hydraulic state of the reactor. The thermal-hydraulic feedback equations in turn depend directly on the flux vector in Equations 1 and 2 . The spatially dependent feedback equations used in this work describe one- and two-phase flow, primary system pressure, fuel assembly heat transfer and hydraulics, and external primary coolant 1oop.

The quasistatic method is concerned primarily with the treatment of the neutronic equations. The treatment of the feedback equations is the same in both the quasistatic and the direct method. Hence, a detailed discussion of the feedback equations is not included in this paper.

\section{THE QUASISTATIC METHOD}

The fundamental assumption in the quasistatic method is that the flux vector may be separated into the product of a shape function that is slowly varying with time, $\psi(\bar{r}, t)$, and a more rapidly varying amplitude function, $T(t)$, as shown below:

$$
\Phi(\bar{r}, t)=\Psi(\bar{r}, t) T(t)
$$


where $\underline{\psi}(\bar{r}, t)$ is normalized such that*

$$
\frac{1}{\bar{p}}\left\langle\underline{w}(\bar{r}, t), \underline{V}^{-1} \Psi(\bar{r}, t)\right\rangle=\text { constant }=\gamma
$$

and $P$ is adjusted so that $y=1$ at $t=0$. $\underline{w}$ is a weight function that is usually selected to be the unperturbed steady state adjoint solution of Equation 1. Equation 4 determines uniquely the separation indicated by Equation 3. More importantly, the condition that $\gamma \simeq 1$ for all time provides a constraint which must be satisfied throughout the transient.

The central idea in the quasistatic method is that a low order approximation with large integration time steps may be used for the calculation of $\Psi(\bar{r}, t)$; whereas, a high order approximation with small integration time steps is used for the calculation of $T(t)$. The separation indicated by Equation 3 should permit the use of larger time steps for the calculation of $\Psi(\bar{r}, t)$ than would be required for the calculation of $\Phi(\bar{r}, t)$. Thus, since a very time-consuming portion of any space-time transient calculation is the spatial calculation at each time step, a reduction in the computation time per transient should be obtained by using Equation 3 provided the additional computation time required for the calculation of $T(t)$ and also the time required to satisfy the constraint equation are not significant. This reduction in computing time should be more evident for transients in which the reactor power is changing rapidly and the spatial flux shape is changing slowly. *The brackets indicate an inner product defined as

$$
\langle\underline{\omega}, \underline{\underline{\theta} Z}\rangle=\int_{\text {Volume }}\left(\omega_{1} \ldots \omega_{\mathrm{G}}\right)\left(\begin{array}{ccc}
\theta_{11} & \cdots \theta_{1 G} \\
\vdots & & \vdots \\
\dot{\theta}_{\mathrm{G} 1} & \ldots & \dot{\theta}_{\mathrm{GG}}
\end{array}\right)\left(\begin{array}{c}
z_{1} \\
\vdots \\
z_{\mathrm{Z}}
\end{array}\right) \mathrm{d} \bar{r}
$$


Substituting Equation 3 into Equations 1 and 2, multiplying by $\underline{\omega}(\bar{r}, t)$, and integrating over the reactor volume yield, after some rearrangement, the following equations:

$$
\begin{aligned}
& \frac{d}{d t} T(t)=\left[\frac{\rho(t)-\bar{B}(t)}{\Lambda(t)}\right] T(t)+\sum_{i=1}^{M} \lambda_{i} \xi_{i}(t)+Q(t) \\
& \frac{d}{d t} \xi_{i}(t)=\frac{\bar{\beta}_{i}(t)}{\Lambda(t)} T(t)-\lambda_{i} \xi_{i}(t) \quad i=1, \ldots, M
\end{aligned}
$$

where

$$
\begin{aligned}
& \frac{\rho}{\Lambda}=\frac{1}{E}\left\langle\underline{\omega},\left\{\nabla \cdot \underline{\underline{D}} \nabla-\underline{A}+\left[(1-\beta) \underline{x}_{p}+\sum_{i=1}^{M} \beta_{i} \underline{x}_{i}\right] \underline{F}^{T}\right\} \psi\right\rangle \\
& \frac{\bar{B}}{\Lambda}=\sum_{i=1}^{M} \frac{\bar{B}_{i}}{\bar{\Lambda}}=\sum_{i=1}^{M} \frac{1}{E}\left\langle\underline{\omega}, \beta_{i} \underline{x}_{i} \underline{F}^{\mathrm{T}} \underline{\psi}\right\rangle \\
& \xi_{i}=\frac{1}{E}\left\langle\underline{\omega}, \underline{I} \underline{x}_{i} C_{i}\right\rangle, Q=\frac{1}{E}\langle\underline{\omega}, \underline{I S}=\underline{S}\rangle \\
& E=\gamma P=\left\langle\underline{\omega}, \underline{\underline{V}}^{-1} \underline{\psi}\right\rangle=\text { constant }
\end{aligned}
$$

Equation 1 may also be expressed as

$$
\begin{aligned}
\underline{V}^{-1} \frac{\partial \Psi}{\partial t}+\underline{\underline{V}}^{-1} \psi \frac{1}{\mathrm{~T}} \frac{\mathrm{dT}}{\mathrm{dt}} & =\left[\nabla \cdot \underline{\underline{D}} \nabla-\underline{\underline{A}}+(1-\beta) \underline{\mathrm{x}}_{\mathrm{p}} \mathrm{F}^{\mathrm{T}}\right] \Psi \\
& +\frac{1}{\mathrm{~T}} \sum_{i=1}^{\mathrm{M}} \underline{x}_{i} \lambda_{i} \mathrm{C}_{i}+\frac{1}{\mathrm{~T}}-
\end{aligned}
$$

$-6-$ 
where $\underline{\psi}=\underline{\psi}(\overline{\mathrm{r}}, t)$ and $C_{i}=C_{i}(\bar{r}, t)$. Integrating Equation 2 from initial time, $t_{0}$ to $t$ gives

$$
\begin{aligned}
C_{i}(\bar{r}, t) & =\beta_{i} \int_{t_{0}}^{t} F^{T}\left(\bar{r}, t^{\prime}\right) \phi\left(\bar{r}, t^{\prime}\right) e^{-\lambda_{i}\left(t-t^{\prime}\right)} d t^{\prime} \\
& +e^{-\lambda_{i}\left(t-t_{0}\right)} C_{i}\left(\bar{r}, t_{0}\right) \quad i=1, \ldots, M
\end{aligned}
$$

Thus, instead of solving Equations 1 and 2 directly, the quasistatic approach is to solve Equations 5-8, along with the constraint equation, Equation 4. It is important to note that no approximations have been made thus far.

\section{Numerical Solution}

Equations 4-8 and the feedback equations are solved numerically using a hierarchy of four different integration time intervals as shown below:

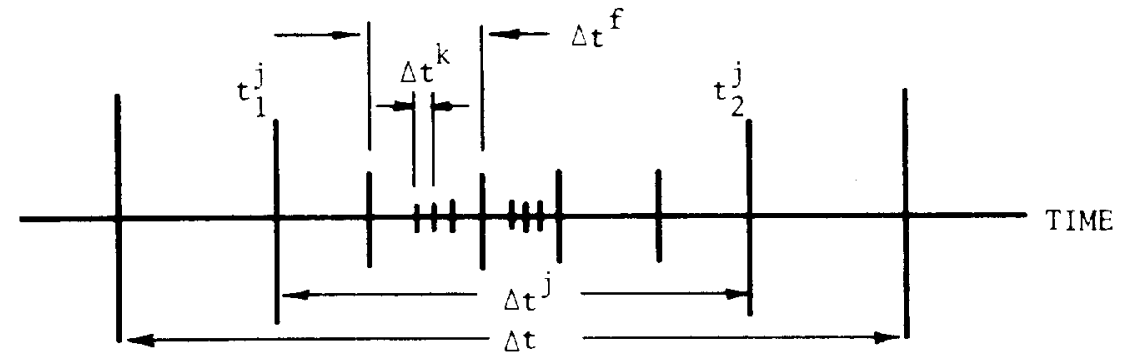

where $\Delta t^{k} \subset \Delta t^{f} \subset \Delta t^{j} \subset \Delta t$

The shape function $\psi(\bar{r}, t)$ is assumed to vary linearly over the largest time interval, $\Delta t$, where for the $n^{\text {th }}$ time interval, $\Delta t_{n}=$ $t_{n}-t_{n-1}$ A simple backward difference in time is used to approximate Equation 7 which gives 


$$
\begin{gathered}
\left\{-\nabla \cdot \underline{\underline{D}} \nabla+\stackrel{A}{=}-(1-\beta) \underline{x}_{p} \underline{F}^{T}+\underline{\underline{V}}^{-1}\left[\frac{1}{T} \frac{d T}{d t}+\frac{1}{\Delta t_{n}}\right]\right\}_{t_{n}} \Psi\left(\bar{r}, t_{n}\right) \\
=\frac{1}{\Delta t_{n}} \underline{V}^{-1} \Psi\left(\bar{r}, t_{n-1}\right)+\left\{\frac{1}{T} \sum_{i=1}^{M} \underline{x}_{i} \lambda_{i} C_{i}+\frac{1}{T} S\right\}_{t_{n}}
\end{gathered}
$$

In concise notation, Equation 9 becomes

$$
\underline{\underline{O}} \Psi\left(\bar{r}, t_{n}\right)=\underline{Z}
$$

where definitions of the operator $\underline{\underline{O}}$ and the driving function $\underline{Z}$ are obvious from comparing Equations 9 and 10.

In Equation 8, the fission density $\underline{F}^{\mathrm{T}} \Phi$ is assumed to vary linearly over $\Delta t_{n}^{j}=t_{n}^{j}-t_{n-1}^{j}$ which gives the following, using $\phi=\underline{\psi}$ :

$$
\begin{aligned}
c_{i}\left(\bar{r}, t_{n}^{j}\right) & =\beta_{i}\left[a_{i-}^{n} F^{T}\left(\bar{r}, t_{n}^{j}\right) \Psi\left(\bar{r}, t_{n}^{j}\right)+b_{i-}^{n} F^{T}\left(\bar{r}, t_{n-1}^{j}\right) \psi\left(\bar{r}, t_{n-1}^{j}\right)\right] \\
& +e^{-\lambda_{i}\left(t_{n}^{j}-t_{n-1}^{j}\right)} C_{i}\left(\bar{r}, t_{n-1}^{j}\right) \quad i=1, \ldots, M
\end{aligned}
$$

where

$$
\begin{aligned}
& a_{i}^{n}=\frac{1}{t_{n}^{j}-t_{n-1}^{j}} \int_{t_{n-1}^{j}}^{t_{n}^{j}} e^{-\lambda i}\left(t_{n}^{j}-t^{\prime}\right)\left(t^{\prime}-t_{n-1}^{j}\right) T\left(t^{\prime}\right) d t^{\prime} \\
& b_{i}^{n}=\frac{1}{t_{n}^{j}-t_{n-1}^{j}} \int_{t_{n-1}^{j}}^{t_{n}^{j}} e^{-\lambda_{i}\left(t_{n}^{j}-t^{\prime}\right)}\left(t_{n}^{j}-t^{\prime}\right) T\left(t^{\prime}\right) d t^{\prime}
\end{aligned}
$$

$a_{i}^{n}$ and $b_{i}^{n}$ are evaluated simultaneously with the solution of Equations 5 and 6 using a fourth order Runge-Kutta approximation over the $\Delta t^{k}$ time intervals. $\rho, \bar{\beta}, \bar{\beta}_{j}$, and $\Lambda$ are computed using their inner product definitions at the $t^{j}$ time points. Quadratic interpolation is used to obtain intermediate values of the coefficients at the $t^{k}$ time points. 
Equation 10 is solved in a somewhat unusual manner which involves the use of Equation 4. Specifically, expand $\underline{\underline{0}}$ as $\underline{O}^{1}-\underline{\underline{O}}^{2}$ where

$$
\begin{aligned}
& \underline{\underline{O}}^{1}=\left\{\nabla \cdot \underline{\underline{D}} \nabla-\underline{\underline{A}}+\underline{\underline{V}}^{-1}\left[\frac{1}{\mathrm{~T}} \frac{\mathrm{dT}}{\mathrm{dt}}+\frac{1}{\Delta t_{n}}\right]\right\}_{t_{n}} \\
& \underline{\underline{O}}^{2}=\left\{(1-\beta) \underline{x}_{p} \underline{F}^{T}\right\}_{t_{n}}
\end{aligned}
$$

Therefore, Equation 10 becomes

$$
\underline{O}^{1} \Psi\left(\bar{r}, t_{n}\right)=\underline{O}^{2} \Psi\left(\bar{r}, t_{n}\right)+\underline{z}
$$

A conventional iterative approach for solving Equation 12 is

as follows:

$$
\underline{0}^{1} \underline{\Psi}^{l+1}=\frac{\underline{0}^{2} \underline{\Psi}^{l}}{a^{l}}+\underline{z}
$$

where $\ell$ is the iteration index and

$$
\alpha^{\ell}=\frac{\left\langle\underline{1}, \underline{\underline{O}} \psi^{\ell}\right\rangle}{\langle\underline{1}, \underline{\underline{I}} \underline{Z}\rangle} \quad \text { with } \underline{1}=(1 \ldots 1)^{\mathrm{T}}
$$

As discussed by Meneley, ${ }^{6}$ numerical difficulties are encountered when using the above procedure for transients in the neighborhood of prompt critical. In order to circumvent this problem, Meneley proposed the following procedure which utilizes Equation 4.

$$
\underline{O}^{1} \underline{\Psi}^{\ell+1}=\underline{\underline{0}} \frac{\underline{\Psi}^{\ell}}{\gamma^{\ell}}+\underline{z}
$$

where

$$
\gamma^{\ell}=\left\langle\underline{w}, \underline{v}^{-1} \underline{\Psi}^{\ell}\right\rangle / \mathrm{P}
$$


The $\ell$ iteration in the above procedure results in a converged value of $\gamma$ and a converged shape function $\underline{\Psi}$. This procedure has been used successfully in the quasistatic codes developed at SRL.

A general description of the solution algorithm is outlined below:

1. Assume everything is known at time $t_{n-1}$.

2. Extrapolate $\Psi$ linearly with respect to time from $\Psi\left(\bar{r}, t_{n-1}\right)$ to $\Psi\left(\bar{r}, t_{n}\right)$.

3. Solve the feedback equations out to $t^{j}$, using time step size $\Delta t^{f}$.

4. Evaluate $\rho, \bar{\beta}, \Lambda$, and $\bar{\beta}_{i}$ at $t_{1}^{j}$ using their inner product definitions.

5. Interpolate $\rho, \bar{\beta}, \Lambda$, and $\bar{\beta}_{i}$ between $t_{n-1}$ and $t_{1}^{j}$ at the $\mathrm{t}^{\mathrm{k}}$ points.

6. Solve Equation 5 and evaluate $a_{i}^{n}, b_{i}^{n}$ out to $t_{1}^{j}$.

7. Update $C_{i}(\bar{r}, t)$ to $t=t_{1}^{j}$ using Equation 11 .

8. If $t_{1}^{j}<t_{n}$, go to next $t^{j}$ point and repeat Steps $3-7$.

9. If $t_{1}^{j}=t_{n}$, solve Equation 14 for a new $\psi\left(\bar{r}, t_{n}\right)$ and a new $\gamma$.

10. If $\gamma_{\text {new }}=1$, go to the next $\Delta t$ interval and repeat Steps 2-9.

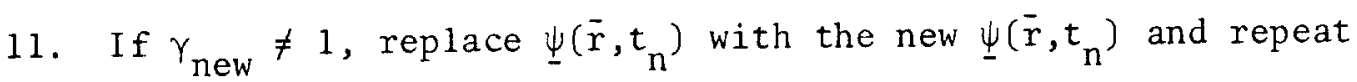
Steps 2-11, omitting Step 3, for the same $\Delta t$ interval or a shorter $\Delta t$ interval.

In the next section, results of calculations using the quasistatic method described above are compared with results obtained 
with the direct finite-difference method. A detailed description of the direct method used in this work is given in Reference 11 . However, it should be pointed out that a fully implicit (i.e., backward) difference approximation for the time derivative of the flux was used in the direct method calculations which is consistent with the treatment of Equations 9 and 10 in the quasistatic method.

\section{RESULTS}

A schematic diagram of the reactor considered in this work is presented in Figure 1 . The reactor is divided into six radial rings and fourteen axial levels, with three mesh points per ring and two mesh points per level, to give an $18 \times 28$ mesh point structure for the spatial neutronic calculations. Moderator flow and assembly heat transfer are calculated using a lumped parameter approximation with lumps defined by the ring-level structure in Figure 1 . The neutronic calculations are performed using two energy groups and six delayed neutron precursor groups. The neutronic and thermalhydraulic constants are representative of a $\mathrm{D}_{2} \mathrm{O}$-moderated and-cooled, uranium-fueled reactor.

Results for two different transients are presented. The first transient is initiated by reducing the coolant flow in some of the assemblies in Ring 1 of the core region (Levels 3-12). The flow is reduced to zero in three seconds. The reactor is initially critical and at full power so that the perturbation causes strong spatial effects [changes in $\underline{\phi(\bar{r})}$ with respect to time] due to the production and quenching of steam. 
Transient 2 is initiated by a 12 -second ramp reduction in the thermal absorption cross section of the core region in Ring 5 (Levels $3-12$ ). The reactor is initially critical but at a very low power so that Transient 2 resembles a startup accident from low power. Because of the nature of the perturbation and the startup from low power, spatial effects are almost insignificant; whereas, the temporal effect in power is quite rapid.

The time step size for the solution of the space-independent equations, $\Delta t^{k}$, is $0.005 \mathrm{sec}$ in all of the quasistatic calculations. A time step size of $\Delta t^{f}=0.05 \mathrm{sec}$ is used for the solution of the thermal-hydraulic feedback equations in the calculations by both methods. The time interval between shape calculations in the quasistatic method and flux calculations in the direct method (denoted by $\Delta t$ ) is the primary variable of interest and will be defined for each case that is presented. The time step size $\Delta t^{j}$ for computing the inner products $\rho, \bar{B}, \Lambda$, and $\bar{\beta}_{i}$ is also a variable of interest that is defined for each case.

The power traces for both transients are presented in Figure 2; the scale on the left is for Transient 1 , and the scale on the right, which is logarithmic, is for Transient 2. The results in Figure 2 were obtained with both methods for a time interval between shape calculations, $\Delta t$ (or flux calculations in the case of the direct method code) equal to $0.05 \mathrm{sec}$. In other words the methods give identical results with $\Delta t=0.05 \mathrm{sec}$. The time step $\Delta \mathrm{t}^{\mathrm{j}}$ in the quasistatic calculation is also equal to $0.05 \mathrm{sec}$. 
In Table 1, the average percent error in power versus time step size is presented for Transient 1 , the transient with the strong spatial effects. The spatial effects may be observed in Table 2 in which values of spatial tilt, where tilt is defined in Figure 3 , are presented at the beginning, the middle, and near the end of the transient for various values of $\Delta t$. The base case for comparison purposes in Table 1 is the transient calculated by the direct method with $\Delta t=0.05 \mathrm{sec}$ which has, of course, a $0 \%$ error. Values for the time interval between inner product calculations are also presented for the results obtained with the quasistatic method. As $\Delta t$ increases, the errors increase moderately in both methods and are approximately equal. However, the direct method encounters numerical problems for the case with $\Delta t=2 \mathrm{sec}$; whereas, the quasistatic method does not.

Results for Transient 2, which has negligible spatial effects, are presented in Tables 3 and 4 . As $\Delta t$ increases, the errors in the direct solution for this transient are considerably larger than the errors in the quasistatic solution which is attributed to the large truncation error that is associated with the time differencing approximation in the direct method. Whereas, in the quasistatic method, the truncation error is kept small by using a very small time step for the amplitude equations. For the cases with $\Delta t=2$ and $4 \mathrm{sec}$ the direct method encounters numerical problems similar to the previous transient while the quasistatic method does not encounter such problems.

Because the accuracy of the quasistatic solution for Transient 2 
is much less sensitive to the size of the time step than the direct method solution, one should be able to obtain a considerable savings in computing cost with the quasistatic code by using larger time steps. Indeed, this is the case as shown in Figure 4 in which the average percent error in power for Transient 2 is plotted versus the CPU* time required by each code. Each data point represents a complete transient calculation by one code. The scatter in the quasistatic data is due to the use of different combinations of $\Delta t$ and $\Delta t^{j}$. Thus, if an average percent error in power of $5 \%$ is desired, the quasistatic code will provide the desired accuracy using about 90 CPU seconds; whereas, the direct method code will use about 440 CPU seconds - a savings of almost a factor of 5 . On the other hand, there are no significant savings in computing costs for Transient 1 as shown in Figure 5 because both methods are about equally sensitive to the time step size due to the strong spatial effects.

\section{CONCLUSIONS}

The quasistatic method was compared with a direct finitedifference method of solving two-dimensional, thermal reactor transient problems with thermal-hydraulic feedback. Calculations using both methods were performed for a cylindrical $(\mathrm{r}-\mathrm{z}), \mathrm{D}_{2} \mathrm{O}$-moderated and-cooled, uranium-fueled reactor.

* Central Processing Unit for the IBM 360, Model 195. 
The results of this study support the following conclusions:

1. The quasistatic method is capable of producing highly accurate results, relative to the direct finite-difference method, for two-dimensional thermal reactor transients with feedback.

2. The quasistatic method offers the flexibility of using larger time steps between shape calculations without encountering numerical problems than the direct method.

3. The quasistatic and direct method codes used in this work are comparable with respect to accuracy and computing costs except for transients with weak spatial effects. For such transients, much larger time steps can be used in the quasistatic code than in the direct method code to achieve a specified accuracy which, in turn, provides a considerable savings in computing costs.

\section{ACKNOWLEDGMENTS}

The author would like to express his sincere appreciation to C. E. Bailey, M. Becker, D. A. Meneley, and J.W. Stewart for their interest and helpful suggestions during the course of this work.

The information contained in this article was developed during the course of work under Contract No. AT (07-2)-1 with the U. S. Energy Research and Development Administration. 


\section{REFERENCES}

1. K. O. OTT and D. A. MENELEY, Nucl. Sci. Eng., 36402 (1969).

2. D. A. MENELEY, K. O. OTT, and E. S. WIENER, "East Reactor Kinetics - The QXI Code," ANL-7769, Argonne National Laboratory (1971).

3. E. L. FUlLER, D. A. MENELEY, and J. A. NASER, Trans. Am. Nucl. Soc., 15, 289 (1972).

4. E. L. FULLER, Trans. Am. Nucl. Soc., 14, 233 (1971).

5. D. A. MENELEY, G. K. LEAF, A, J. LINDEMAN, T. A. DALY, and W. T. SHA, "A Kinetics Model for Fast Reactor Analysis in Two Dimensions," Dynomics of Nuclear Sustems, D. Hetrick, Ed., pp. 483-500, The University of Arizona Press, Tucson, Arizona (1972).

6. W. T. SHA, T. A. DALY, A. J. LINDEMAN, E. L. FULLER, D. A. MENELEY, and G. K. LEAF, "Two-Dimensional Fast-Reactor Disassembly Analysis with Space-Time Kinetics," Proc. Conf. New Developments in Reactor Mathematics and Applications, Idaho Falls, Idaho, March 29-31, 1971, CONF-710302,

7. L. MAYER and H. BACHMANN, "Two-Dimensional Calculation of Reactor Excursions with the Quasistatic Method, "CREST Meeting on Reactivity Effects in Large Power Reactors, Ispra, Italy, October 28-30, 1970, CONF-701019.

8. L. MAYER and H. BACHMANN, "Two-Dimensional Reactor Dynamics with the Quasistatic Method," Reactor Meeting, Bonn, Germany March 30 - Apriz 2, 1971, CONF-710346.

9. H. L. DODDS, JR., J. W. STEWART, and C. E. BAILEY, Trans. Am. Nucl. Soc., 15, 786 (1972).

10. H. L. DODDS, JR., P. B. PARKS, C. E. BAILEY, N. P. BAUMANN, R. L. CURRIE, and J. W. STEWART, Trans. Am. Nucl. SOc., 16, 292 (1973).

11. J. B. YASINSKY, M. NATELSON, and L. A. HAGEMAN, TWIGL - A Program to Solve the Two-Dimensional, Two-Group, Space-Time Neutron Diffusion Equations with Temperature Feedback, WAPD-TM-743, Bettis Atomic Power Laboratory (1968).

12. H. C. HONECK, J. E. SUICH, J. C. JENSEN, C. E. BAILEY, and J. W. STEWART, "JOSHUA - A Reactor Physics Computational System," Proc. Conf. Effective Use of Computers in the Nuclear Industry, Knowilie, Tennessee, Apriz 21-23, 1969, CONF-690401. 
TABLE 1

$\begin{array}{llll}\begin{array}{l}\text { Average Percent Error in Power versus Time Step } \\ \text { for Transient 1 }\end{array} & \\ \Delta t \text {, sec Direct, } \% & \Delta t^{j} \text {, sec } & \text { Quasistatic, \% } \\ 0.05 & 0 & 0.05 & 0.62 \\ 0.2 & 3.07 & 0.05 & 1.54 \\ & & 0.2 & 2.89 \\ 0.5 & 3.69 & 0.05 & 2.50 \\ & & 0.5 & 3.22 \\ 1.0 & 5.69 & 0.05 & 5.66 \\ & & 1.0 & 6.27 \\ 2.0 & a & 1.0 & 8.08\end{array}$

a. Numerical difficulties encountered.

TABLE 2

Spatial Tilt versus Time $^{a}$ for Transient 1

\begin{tabular}{|c|c|c|c|c|}
\hline \multirow[b]{2}{*}{$\Delta t$, sec } & \multicolumn{2}{|c|}{ Direct } & \multicolumn{2}{|c|}{ Quasistatic b } \\
\hline & $\bar{t}=14 \mathrm{sec}$ & $t=27 \mathrm{sec}$ & $t=14 \mathrm{sec}$ & $t=27 \mathrm{sec}$ \\
\hline 0.05 & 1.66 & 0.67 & 1.64 & 0.68 \\
\hline 1.00 & 1.74 & 0.71 & 1.79 & 0.70 \\
\hline 2.00 & 4.75 & $c$ & 1.75 & 0.79 \\
\hline
\end{tabular}

a. At $t=0$, tilt $=0.78$.

b. $\Delta t^{j}=0.05 \mathrm{sec}$.

c. Numerical difficulties encountered. 
TABLE 3

Average Percent Error in Power versus Time Step Size for Transient 2

$\begin{array}{lcll}\Delta t, \text { sec } & \text { Direct, \% } & \Delta t^{j}, \text { sec } & \text { Quasistatic, \% } \\ 0.05 & 0 & 0.05 & 0.23 \\ 0.50 & 18.80 & 0.05 & 0.24 \\ 1.00 & 65.20 & 0.05 & 0.49 \\ & & 1.00 & 3.21 \\ 2.00 & a & 0.05 & 0.62 \\ & & 1.00 & 2.98 \\ 4.00 & a & 1.00 & 4.38\end{array}$

a. Numerical difficulties encountered.

TABLE 4

Spatial Tilt versus Time $^{\alpha}$ for Transient 2

\begin{tabular}{|c|c|c|c|c|c|c|}
\hline \multicolumn{4}{|c|}{ Direct } & \multicolumn{3}{|c|}{ Quasistatic } \\
\hline$\Delta t$, sec & $t=12 \mathrm{sec}$ & $t=20 \mathrm{sec}$ & $t=28 \mathrm{sec}$ & $t=12 \mathrm{sec}$ & $t=20 \mathrm{sec}$ & $t=28 \mathrm{sec}$ \\
\hline 0.05 & 0.83 & 0.83 & 0.86 & 0.83 & 0.83 & 0.86 \\
\hline 1.00 & 0.83 & 0.85 & 0.87 & 0.83 & 0.83 & 0.86 \\
\hline 2.00 & c & $c$ & $c$ & 0.83 & 0.83 & 0.86 \\
\hline 4.00 & $c$ & $c$ & $c$ & 0.83 & 0.83 & 0.86 \\
\hline
\end{tabular}

a. At $t=0$, tilt $=0.76$.

b. $\Delta t^{j}=0.05 \mathrm{sec}$.

c. Numerical difficulties encountered. 


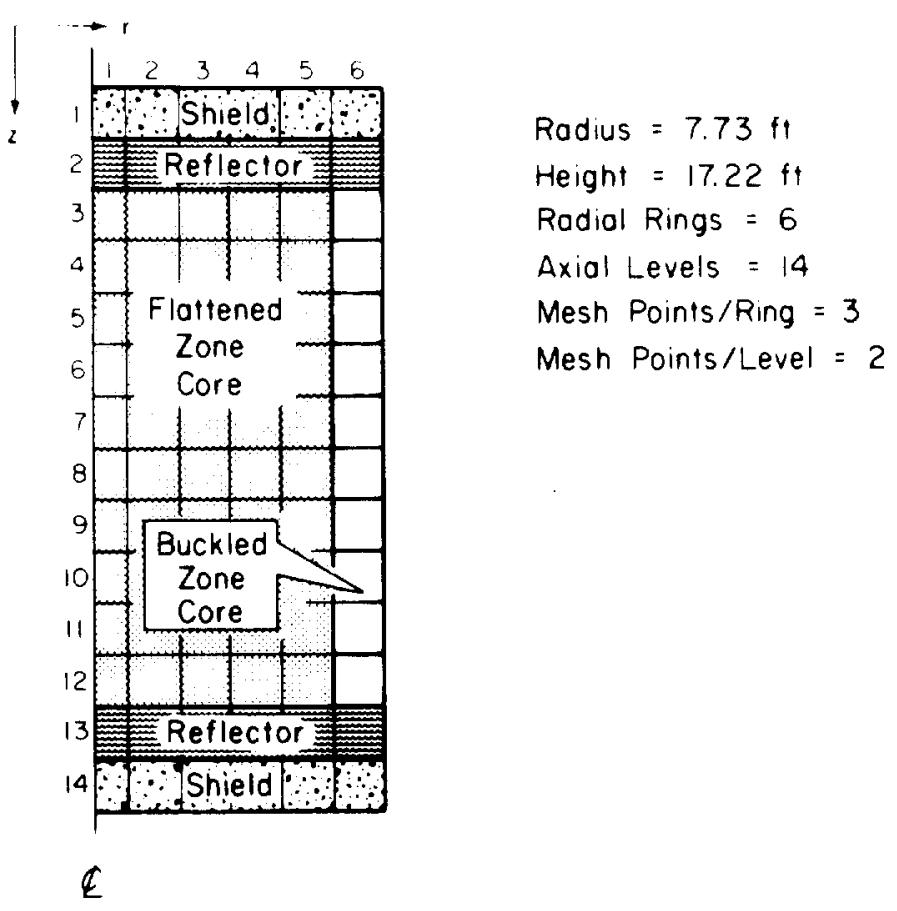

FIGURE 1 Schematic Diagram of Reactor

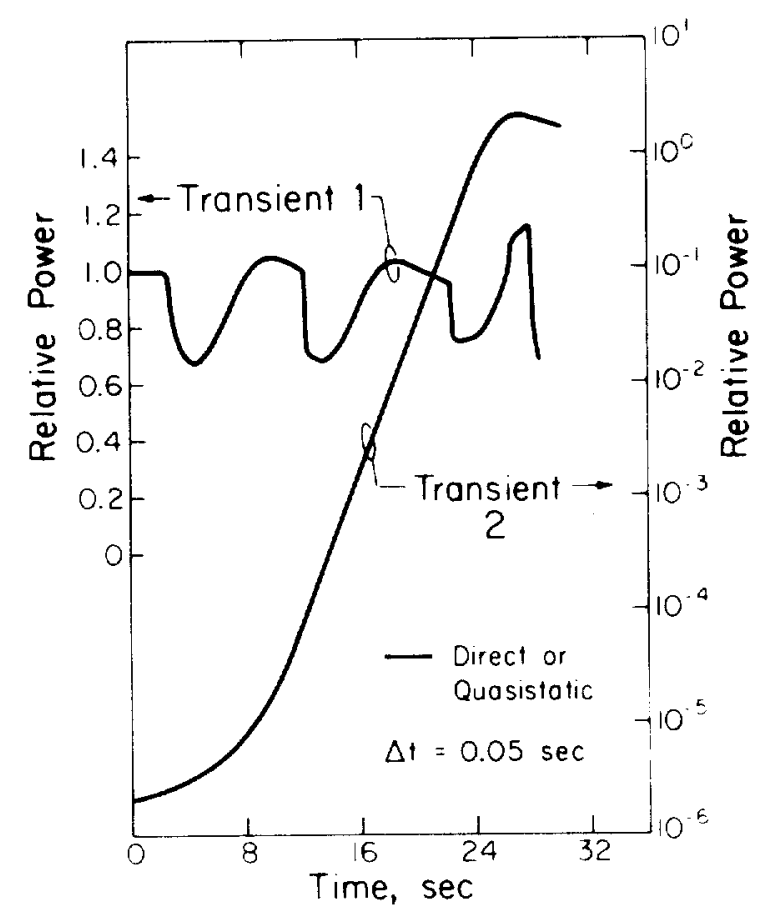

FIGURE 2 Relative Power versus Time for Transients 1 and 2 


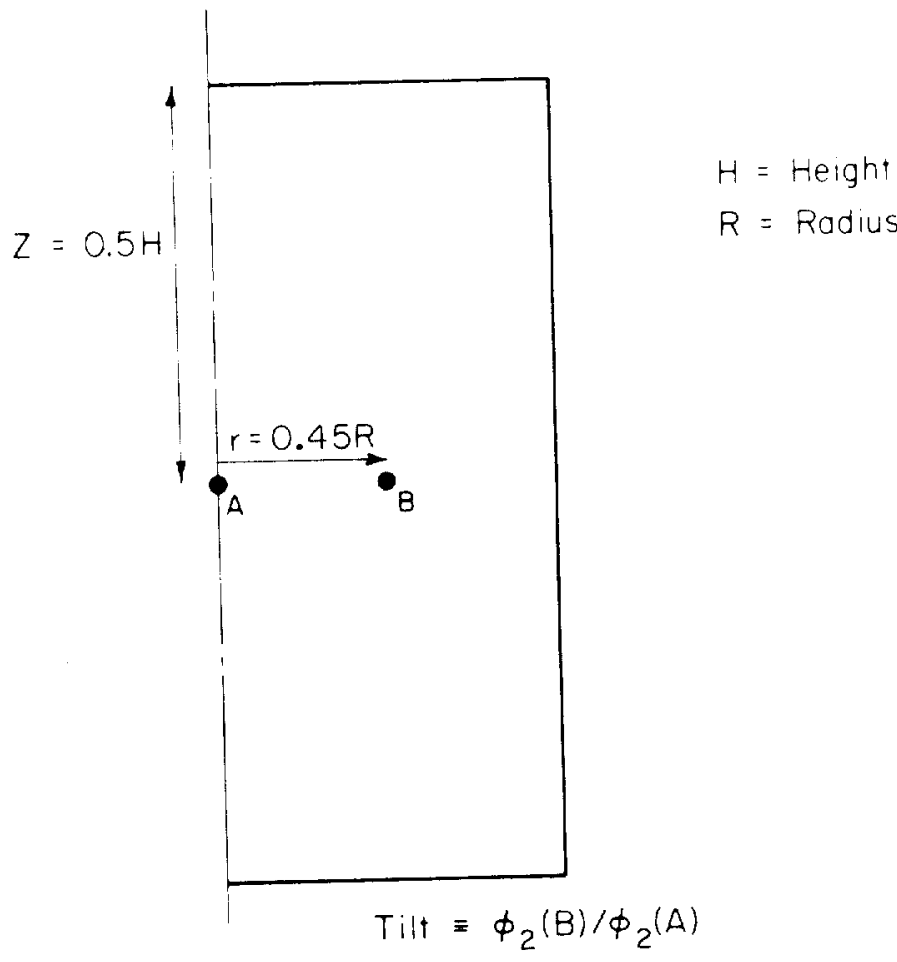

FIGURE 3 Definition of Spatial Flux Tilt 


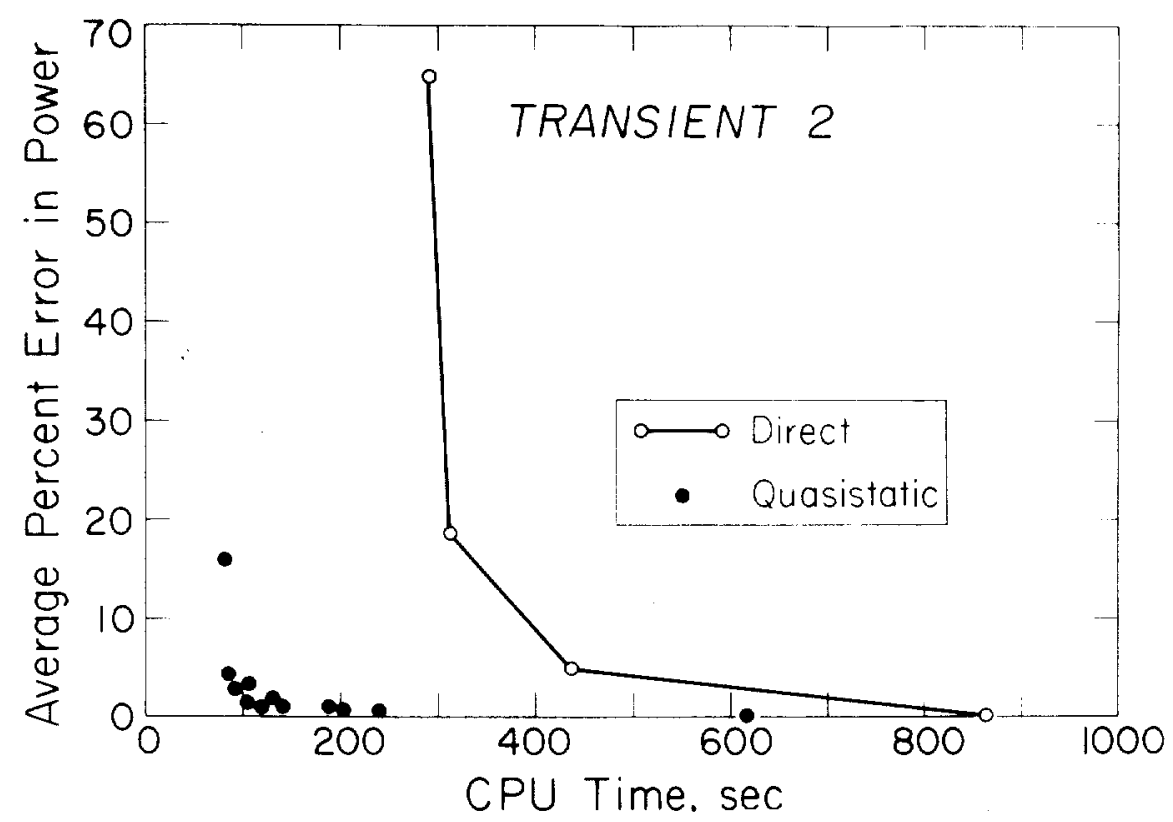

FIGURE 4 Average Percent Error in Power versus CPU Time for Transient 2

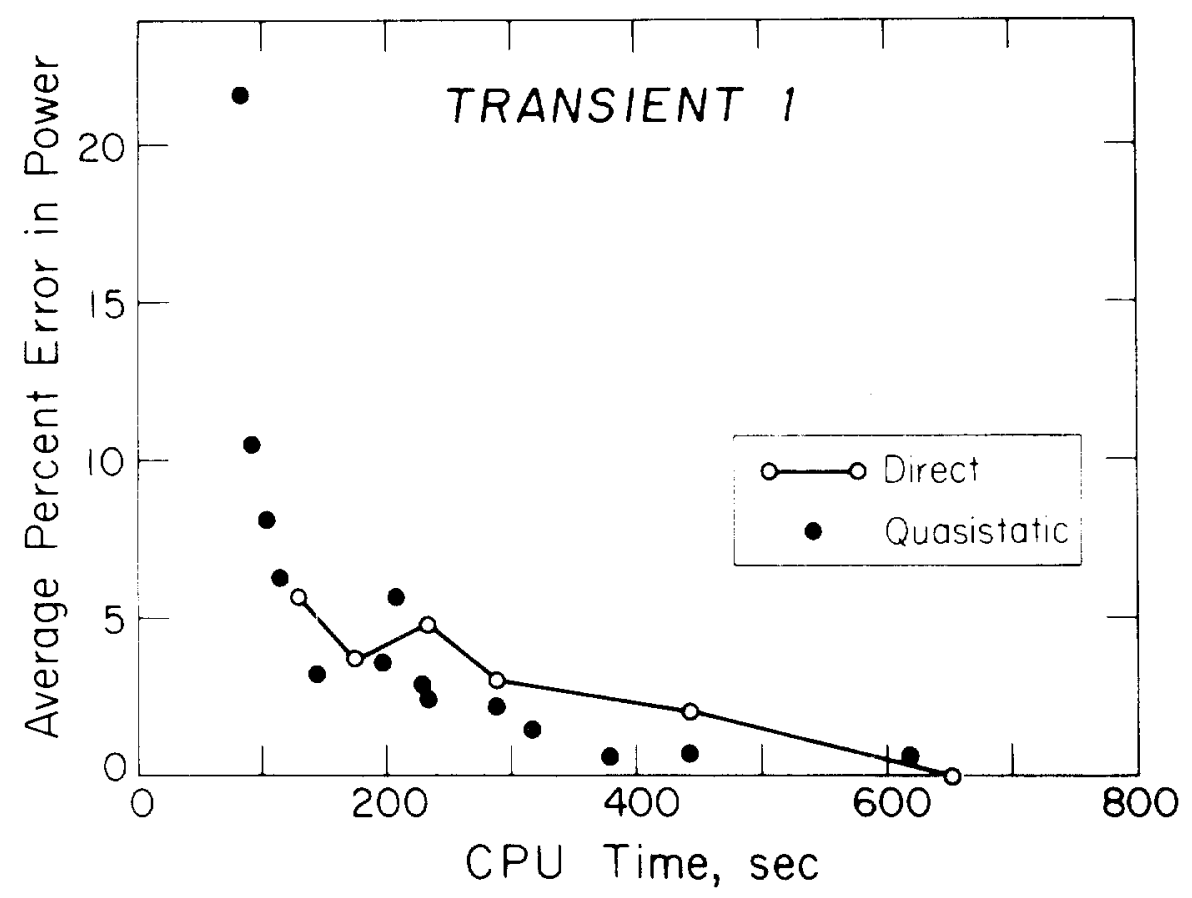

FIGURE 5 Average Percent Error in Power versus CPU Time for Transient 1 